\title{
Effect of nitrogen on corrosion behaviour of a novel high nitrogen medium-entropy alloy CrCoNiN manufactured by pressurized metallurgy
}

\author{
Hao Feng ${ }^{\mathrm{a}}$, Huabing $\mathrm{Li}^{\mathrm{a}, *}$, Xiaolei $\mathrm{Wu}^{\mathrm{b}, *}$, Zhouhua Jiang ${ }^{\mathrm{a}}$, Si Zhao ${ }^{\mathrm{a}}$, Tao Zhang ${ }^{\mathrm{c}}$, Dake Xu ${ }^{\mathrm{c}}$, \\ Shucai Zhang ${ }^{\mathrm{a}}$, Hongchun Zhu ${ }^{\mathrm{a}}$, Binbin Zhang ${ }^{\mathrm{a}}$, Muxin Yang ${ }^{\mathrm{b}}$ \\ a School of Metallurgy, Northeastern University, Shenyang 110819, China \\ ${ }^{\mathrm{b}}$ State Key Laboratory of Nonlinear Mechanics, Institute of Mechanics, Chinese Academy of Sciences, Beijing 100190, China \\ c School of Materials Science and Engineering, Northeastern University, Shenyang 110819, China
}

\section{A R T I C L E I N F O}

\section{Article history:}

Received 28 December 2017

Received in revised form 31 January 2018

Accepted 6 March 2018

Available online 3 April 2018

\section{Keywords:}

Medium-entropy alloy

Nitrogen

Pitting corrosion

Passive film

Metastable pitting

\begin{abstract}
A B S T R A C T
A novel high nitrogen medium-entropy alloy $\mathrm{CrCoNiN}$, which had higher strength and slightly lower ductility than $\mathrm{CrCoNi}$ alloy, was successfully manufactured by pressurized metallurgy. The microstructure and corrosion behaviour were investigated by microscopic, electrochemical and spectroscopic methods. The results indicated that nitrogen existed in the form of $\mathrm{Cr}_{2} \mathrm{~N}$ precipitates and uniformly distributed $\mathrm{N}$ atoms, and nitrogen alloying significantly refined the grain size. Besides, nitrogen enriched on the outmost surface of passive film and metal/film interface as ammonia $\left(\mathrm{NH}_{3}\right.$ and $\left.\mathrm{NH}_{4}{ }^{+}\right)$and $\mathrm{CrN}$, respectively. The significant improvement of corrosion resistance of $\mathrm{CrCoNiN}$ was attributed to the lower metastable pitting susceptibility together with thicker, less defective and more compact passive film.
\end{abstract}

(c) 2018 Published by Elsevier Ltd on behalf of The editorial office of Journal of Materials Science \& Technology.

\section{Introduction}

The newly explored high-entropy alloys, being composed of multiple principle elements in equimolar or near-equimolar ratio [1], have drawn extensive attentions [2,3]. In recent years, various high-entropy alloys have been developed which exhibit excellent combination of strength and ductility especially at low temperature [4,5], high wear resistance [6] and good thermal stability [7], etc. The three-component CrCoNi medium-entropy alloy, which has low mixing configurational entropy $\left(\triangle S_{\text {conf }}=1.10 R\right)$, possesses high work hardenability, excellent ductility and fracture resistance [5,8]. However, considering the demand for engineering application, it may not satisfy the requirement of high yield strength at elevated temperatures $[9,10]$. Therefore, mechanical alloying together with spark plasma sintering (MA+SPS) [9] and precipitation hardening by adding a small amount of $\mathrm{Al}$ and $\mathrm{Ti}[10]$ were investigated to increase the strength of $\mathrm{CrCoNi}$ alloy. Besides, as an important strengthening mechanism, interstitial strengthening by boron [11] and carbon [12] has be adopted to improve the mechanical proper-

\footnotetext{
* Corresponding authors.

E-mail addresses: huabing_li@163.com (H. Li), xlwu@imech.ac.cn (X. Wu).
}

ties of high-entropy alloys. However, both elements deteriorated the properties of alloys because boron worsened the corrosion resistance [13] and carbon promoted the sensitivity of precipitation [14].

The beneficial effects of nitrogen on mechanical properties of austenitic [15-18], duplex [19,20] and martensitic [21,22] stainless steels have been widely reported. Besides, nitrogen in stainless steels could decrease the metastable pitting susceptibility [16], promote passivation and stability of passive film [15,23,24], thus enhancing the corrosion resistance of stainless steels [25]. Therefore, it can be inferred that nitrogen has a great potential in improving the properties of CrCoNi medium-entropy alloy. Considering the extremely low nitrogen solubility in $\mathrm{Ni}$ and Co based alloys at atmospheric pressure [26], pressurized metallurgy, as an effective technique to enhance nitrogen content in stainless steels and alloys [21,27,28], has been firstly used to manufacture the novel high nitrogen medium-entropy alloy CrCoNiN by the authors. Recently, Wu [29] reported that the CrCoNiN alloy exhibited an obvious increase in strength and a slight decrease in ductility compared with $\mathrm{CrCoNi}$ alloy (Table 1 ). However, the effect of nitrogen on corrosion resistance of $\mathrm{CrCoNiN}$ alloy is still unclear. 
Table 1

Chemical compositions and mechanical properties of the investigated medium-entropy alloys.

\begin{tabular}{|c|c|c|c|c|c|c|c|c|}
\hline \multicolumn{6}{|c|}{ Chemical composition } & \multicolumn{3}{|c|}{ Mechanical properties (at $25^{\circ} \mathrm{C}$ ) } \\
\hline Alloys & & $\mathrm{Cr}$ & Co & $\mathrm{Ni}$ & $\mathrm{N}$ & Yield strength (MPa) & Ultimate tensile strength (MPa) & Elongation (\%) \\
\hline \multirow[t]{2}{*}{$\mathrm{CrCoNi}$} & wt $\%$ & 30.58 & 34.71 & 34.71 & - & 205.6 & 638.6 & 68.9 \\
\hline & at $\%$ & 33.25 & 33.31 & 33.44 & - & & & \\
\hline \multirow[t]{2}{*}{ CrCoNiN } & $w t \%$ & 30.45 & 34.56 & 34.55 & 0.44 & 374.4 & 1161.1 & 43.0 \\
\hline & at $\%$ & 32.68 & 32.73 & 32.84 & 1.75 & & & \\
\hline
\end{tabular}

The aim of the present paper is to reveal the effect of nitrogen on microstructure and corrosion resistance of $\mathrm{CrCoNiN}$ alloy. The microstructure characterizations were analysed employing optical microscope (OM), field emission scanning electron microscope (FE-SEM), transmission electron microscope (TEM) and threedimensional atom probe (3DAP). The corrosion resistance was investigated by potentiodynamic and cyclic polarization together with critical pitting temperature (CPT) tests. In addition, characteristic of passive film was analysed with Mott-Schottky and X-ray photoelectron spectrometer (XPS) analyses. Finally, the effects of nitrogen on passive film and metastable pitting initiation on $\mathrm{CrCoNi}$ alloy were discussed.

\section{Experimental procedure}

\subsection{Materials and heat treatment}

The $\mathrm{CrCoNi}$ and $\mathrm{CrCoNiN}$ medium-entropy alloys were produced from high purity elements $\mathrm{Cr}$ (99.17\%), Co (99.98\%) and $\mathrm{Ni}(99.96 \%)$ in a $25 \mathrm{~kg}$ pressurized induction furnace. The $\mathrm{CrCoNi}$ alloy was melted and poured into ingot mould under argon atmosphere, and the CrCoNiN alloy was melted and poured under nitrogen pressure of 1.0 MPa and 2.0 MPa, respectively. Before pouring, nickel magnesium (NiMg) master alloy and metallic cerium (Ce) were added into the melt for deoxidization and desulfurization. Nitrogen was added into $\mathrm{CrCoNiN}$ alloy through gas nitriding during melting and pouring under high nitrogen pressure. The chemical compositions of the alloys are shown in Table 1 . Then the heat treatment and hot working processes were performed using a muffle furnace under air atmosphere. The ingots were homogenized at $1200^{\circ} \mathrm{C}$ for $24 \mathrm{~h}$, and then hot forged to $70 \mathrm{~mm} \times 12 \mathrm{~mm}$ plates in the temperature range of $1200^{\circ} \mathrm{C}-950^{\circ} \mathrm{C}$. Finally, the plates were solution treated at $1150^{\circ} \mathrm{C}$ for $2 \mathrm{~h}$ followed by water quenching.

\subsection{Microstructure observation}

The specimens with dimensions of $10 \mathrm{~mm} \times 10 \mathrm{~mm} \times 6 \mathrm{~mm}$ were machined from the plates. They were wet ground with successive grade SiC papers up to 2000 grit, polished with $1.5 \mu \mathrm{m}$ diamond paste, and then etched using the reagent consisting of $1 \mathrm{~g} \mathrm{FeCl}_{3}+5 \mathrm{~mL} \mathrm{HCl}+1 \mathrm{~mL} \mathrm{HNO}_{3}+10 \mathrm{~mL} \mathrm{H}_{2} \mathrm{O}$. The microstructure of the specimens were observed using an Olympus DSX510 optical microscope (OM) and a Carl-Zeiss Ultra Plus field emission scanning electron microscope (FE-SEM) equipped with an energy dispersive spectroscopy (EDS) system. Thin foils for transmission electron microscopy (TEM) observation were mechanically ground with SiC paper to the thickness of $30 \mu \mathrm{m}$ and punched into discs with the diameter of $3 \mathrm{~mm}$. After that, the discs were Ar-ion milled and then analysed using an FEI Tecnai F30 microscope. To investigate the elemental distribution in $\mathrm{CrCoNiN}$ alloy, the three-dimensional atom probe (3DAP) analysis was performed with a Cameca local electrode atom probe (LEAP 4000X HR). The data were reconstructed and analysed with Imago Visualization and Analysis Software IVAS $^{\mathrm{TM}}$ 3.6.8).

\subsection{Electrochemical measurements}

The electrochemical measurements were conducted using a Gamry Reference 600 potentiostat with a three-electrode cell. The working electrode was mounted in epoxy resin with an exposure area of $1.0 \mathrm{~cm}^{2}$, and then abraded with $\mathrm{SiC}$ papers up to 2000 grit before the experiments. A platinum plate was served as the counter electrode and a saturated calomel electrode (SCE) as the reference electrode. The electrolyte was $3.5 \mathrm{wt} \% \mathrm{NaCl}$ solution in naturally aerated condition, and the temperature was maintained at $30^{\circ} \mathrm{C}$, $50^{\circ} \mathrm{C}$ and $70^{\circ} \mathrm{C}$ in water bath. Prior to the electrochemical measurements, the working electrode was cathodically polarized at $-1.0 \mathrm{~V}_{\mathrm{SCE}}$ for $5 \mathrm{~min}$ to remove the air formed oxide layer and then stabilized in the electrolyte for $30 \mathrm{~min}$ to achieve the steady state condition. The potentiodynamic polarization test was performed at a sweep rate of $0.333 \mathrm{mV} / \mathrm{s}$ from $-0.3 \mathrm{~V}$ below open circuit potential (OCP) in the anodic direction, and the test was terminated when the current density exceeded $1 \mathrm{~mA} / \mathrm{cm}^{2}$. The cyclic polarization test was carried out at a sweep rate of $1 \mathrm{mV} / \mathrm{s}$ from $-0.3 \mathrm{~V}$ below OCP, and the scan was reversed to the starting potential when the current density reached $1 \mathrm{~mA} / \mathrm{cm}^{2}$. The pitting potential $\left(E_{\text {pit }}\right)$ was determined when the current density reached $100 \mu \mathrm{A} / \mathrm{cm}^{2}$. The potentiostatic measurement was carried out to measure the critical pitting temperature (CPT). The anodic potential of $600 \mathrm{mV}_{\mathrm{SCE}}$ was applied to the working electrode, and the electrolyte temperature was increased at the rate of $1^{\circ} \mathrm{C} / \mathrm{min}$ with the initial temperature of $10^{\circ} \mathrm{C}$. The $\mathrm{CPT}$ was defined as the temperature at which the current density reached $100 \mu \mathrm{A} / \mathrm{cm}^{2}$ and stayed above this value for $60 \mathrm{~s}$ [30].

In order to examine the semiconductor property of the passive film, Mott-Schottky measurement was preformed after forming the passive film at $0 \mathrm{mV}_{\mathrm{SCE}}$ for $3600 \mathrm{~s}$. The Mott-Schottky measurement was carried out at a fixed frequency of $1000 \mathrm{~Hz}$ using a $5 \mathrm{mV}$ amplitude voltage. The potential sweep was performed at a step rate of $25 \mathrm{mV}$ in the passive zone according to the potentiodynamic polarization curves. All the electrochemical measurements were repeated three times.

\subsection{XPS analysis}

The working electrodes for passive film analyses were polished with $1.5 \mu \mathrm{m}$ diamond paste. The passive films on $\mathrm{CrCoNi}$ and $\mathrm{CrCoNiN}$ alloys were formed under the potential of $0 \mathrm{mV}_{\mathrm{SCE}}$ for $3600 \mathrm{~s}$ at $50^{\circ} \mathrm{C}$ after the air formed oxide layer was removed. $\mathrm{X}$-ray photoelectron spectrometer (XPS) was employed to analyse the chemical composition of the passive film using ESCALAB250 equipped with $\mathrm{Al} \mathrm{K \alpha}(1486.6 \mathrm{eV}, 150 \mathrm{~W}) \mathrm{X}$-ray source, and the photoelectron take-off angle was $90^{\circ}$. The depth profile information was obtained using argon ions sputtering (base pressure: $1.33 \times 10^{-5} \mathrm{~Pa}$, energy: $2 \mathrm{keV}$, current: $2.0 \mu \mathrm{A} / \mathrm{cm}^{2}$ ) over an area of $2 \mathrm{~mm} \times 2 \mathrm{~mm}$. XPS survey spectra were recorded to identify the elements in the passive film, and then the high resolution spectra of $\mathrm{Cr} 2 \mathrm{p}, \mathrm{Ni} 2 \mathrm{p}, \mathrm{Co} 2 \mathrm{p}, \mathrm{O} 1 \mathrm{~s}, \mathrm{~N} 1 \mathrm{~s}$ and $\mathrm{C} 1 \mathrm{~s}$ were recorded. The binding energies were corrected according to the internal standard of $\mathrm{C} 1 \mathrm{~s}$ peak at $284.6 \mathrm{eV}$. The spectra were fitted using XPSPEAK 4.0 software by reference to a database [31]. 

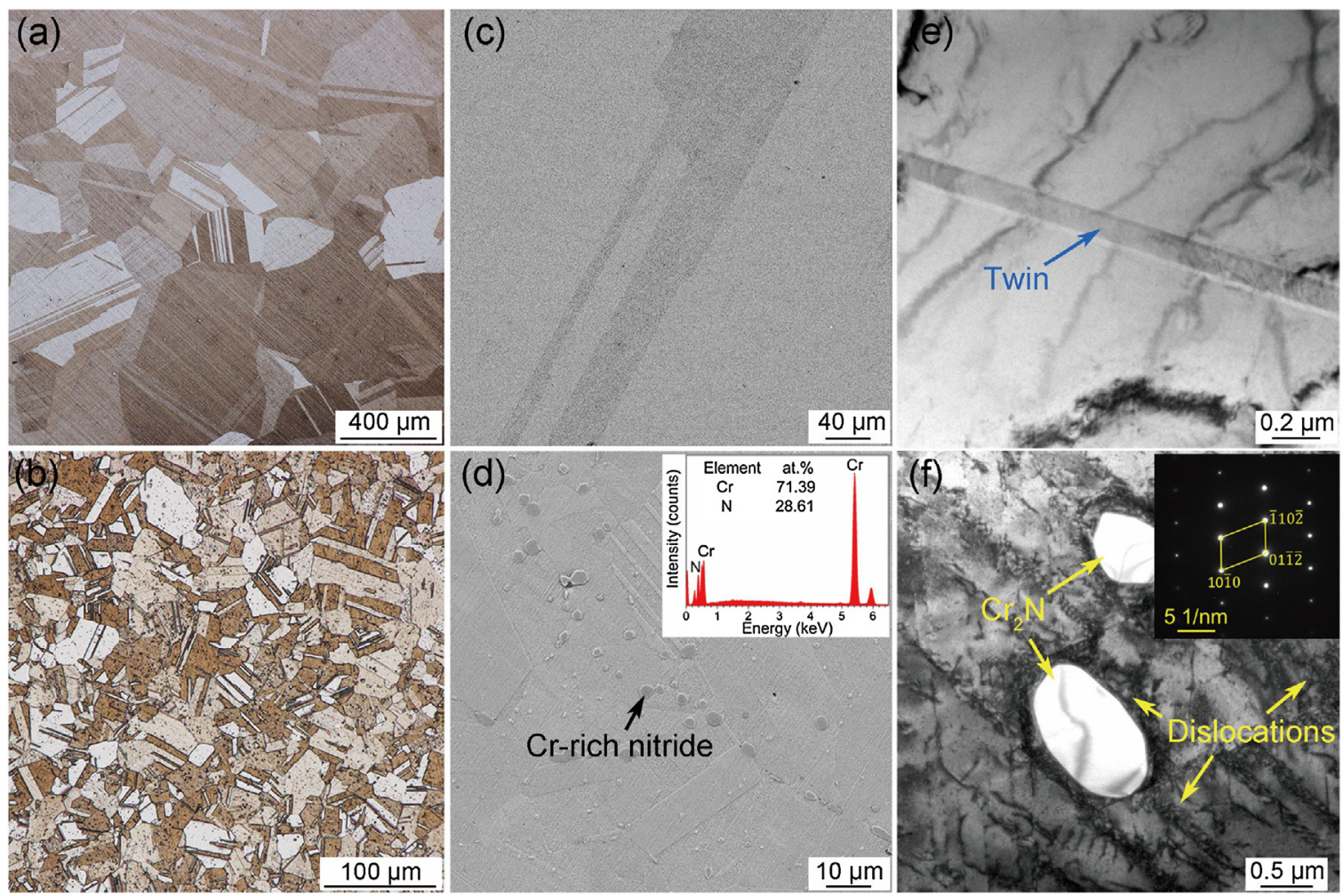

Fig. 1. OM, SEM and TEM micrographs of (a), (c), (e) CrCoNi and (b), (d), (f) CrCoNiN medium-entropy alloys.
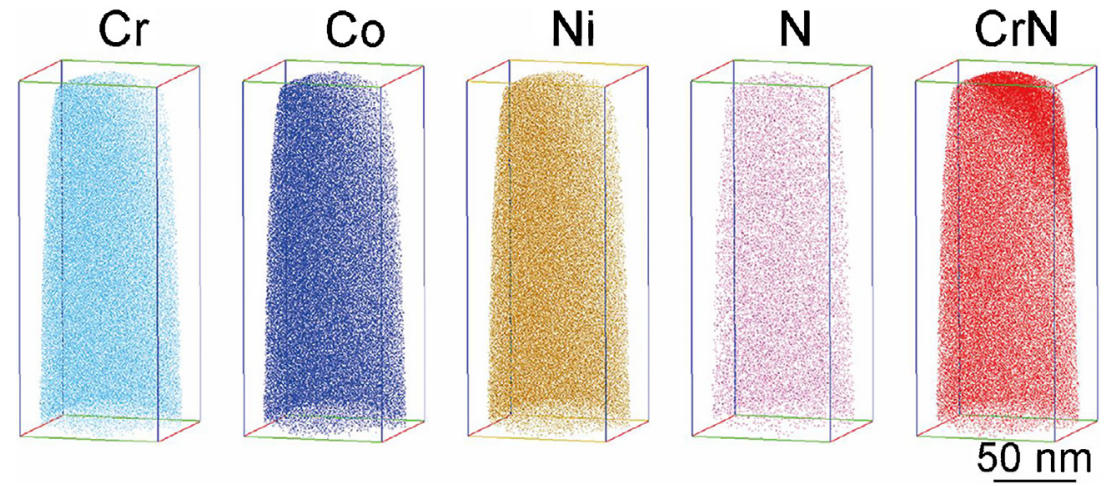

Fig. 2. 3D atom-by-atom tomographic reconstruction (box size $87 \mathrm{~nm} \times 87 \mathrm{~nm} \times 216 \mathrm{~nm}$ ) of CrCoNiN medium-entropy alloy.

\section{Results}

\subsection{Microstructure characterizations}

The OM micrographs of CrCoNi and CrCoNiN medium-entropy alloys are shown in Fig. 1(a) and (b). The microstructure of both alloys consisted of austenite grains with annealing twins, and the grains were remarkably refined by nitrogen alloying. The SEM micrographs (Fig. 1(c) and (d)) show that no precipitate existed in $\mathrm{CrCoNi}$ alloy, whereas massive precipitates were observed in CrCoNiN alloy. Based on the chemical composition of precipitates by EDS analysis, the precipitates were preliminarily determined to be $\mathrm{Cr}$-rich nitrides. The TEM micrograph of CrCoNi alloy in Fig. 1(e) reveals annealing twin with very low dislocation density. However, the CrCoNiN alloy (Fig. 1(f)) exhibits a high dislocation density especially around the precipitates. Besides, the precipitates in $\mathrm{CrCoNiN}$ alloy were confirmed to be $\mathrm{Cr}_{2} \mathrm{~N}$ according to the SAD pattern. Based on the microstructure observation, the addition of nitrogen obvi- ously reduced the austenite grain size and induced the formation of $\mathrm{Cr}_{2} \mathrm{~N}$ precipitates together with high dislocation density.

The 3D atom-by-atom tomographic reconstruction of $\mathrm{CrCoNiN}$ medium-entropy alloy is illustrated in Fig. 2. It indicates that the $\mathrm{Cr}, \mathrm{Co}, \mathrm{Ni}$ and $\mathrm{N}$ elements were almost uniformly distributed in the alloy. It is noteworthy that both uniform distribution and segregation of $\mathrm{CrN}$ were observed. The existence of uniformly distributed $\mathrm{CrN}$ was attributed to the field evaporation of $\mathrm{N}$ atom together with $\mathrm{Cr}$ atom, and the segregated $\mathrm{CrN}$ was ascribed to $\mathrm{Cr}_{2} \mathrm{~N}$ precipitate. Therefore, nitrogen exists in $\mathrm{CrCoNiN}$ alloy in the form of $\mathrm{Cr}_{2} \mathrm{~N}$ precipitates and uniformly distributed $\mathrm{N}$ atoms.

\subsection{Electrochemical measurements}

Fig. 3(a) and (b) shows the potentiodynamic polarization curves of $\mathrm{CrCoNi}$ and $\mathrm{CrCoNiN}$ medium-entropy alloys, respectively. The $\mathrm{CrCoNi}$ alloy exhibited a wide passive range at $30^{\circ} \mathrm{C}$ in which the current density kept almost stable. As the temperature increased 

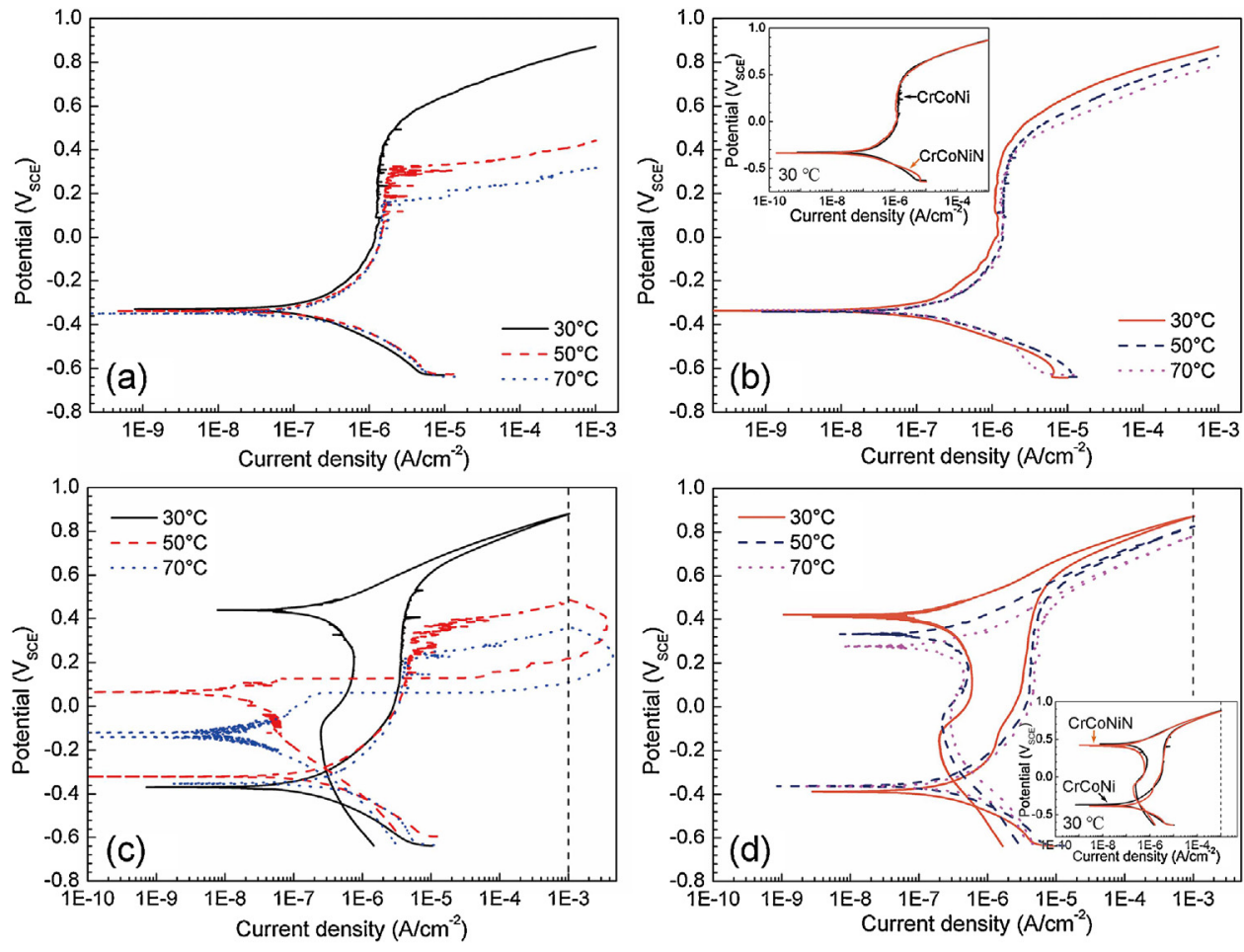

Fig. 3. Potentiodynamic polarization curves and cyclic polarization curves of (a)(c) CrCoNi and (b)(d) CrCoNiN medium-entropy alloys.

Table 2

Potentiodynamic and cyclic polarization parameters of the investigated medium-entropy alloys.

\begin{tabular}{|c|c|c|c|c|c|c|}
\hline \multirow[t]{2}{*}{ Alloys } & \multirow{2}{*}{$\begin{array}{l}\text { Temperature } \\
\left({ }^{\circ} \mathrm{C}\right)\end{array}$} & \multicolumn{2}{|c|}{ Potentiodynamic polarization } & \multicolumn{3}{|c|}{ Cyclic polarization } \\
\hline & & $I_{\text {corr }} \times 10^{7}\left(\mathrm{~A} / \mathrm{cm}^{2}\right)$ & $E_{\text {pit }}\left(\mathrm{mV}_{\mathrm{SCE}}\right)$ & $E_{\text {pit }}\left(\mathrm{mV}_{\mathrm{SCE}}\right)$ & $E_{\mathrm{rp}}\left(\mathrm{mV}_{\mathrm{SCE}}\right)$ & $I_{\max }\left(\mathrm{mA} / \mathrm{cm}^{2}\right)$ \\
\hline \multirow[t]{3}{*}{$\mathrm{CrCoNi}$} & 30 & $1.40 \pm 0.33$ & $744.9 \pm 2.6$ & $762.8 \pm 2.2$ & $E_{\text {pit }}$ & $1.1 \pm 0.0$ \\
\hline & 50 & $2.85 \pm 0.34$ & $336.7 \pm 24.6$ & $421.3 \pm 8.1$ & $147.3 \pm 19.2$ & $3.4 \pm 0.2$ \\
\hline & 70 & $3.18 \pm 0.96$ & $240.7 \pm 16.1$ & $270.0 \pm 10.5$ & $55.3 \pm 6.8$ & $3.6 \pm 0.9$ \\
\hline \multirow[t]{3}{*}{ CrCoNiN } & 30 & $1.39 \pm 0.35$ & $782.4 \pm 9.7$ & $763.1 \pm 1.3$ & $E_{\text {pit }}$ & $1.0 \pm 0.0$ \\
\hline & 50 & $2.34 \pm 0.44$ & $712.0 \pm 8.7$ & $711.6 \pm 4.0$ & $E_{\text {pit }}$ & $1.0 \pm 0.0$ \\
\hline & 70 & $2.75 \pm 0.77$ & $663.4 \pm 35.1$ & $660.9 \pm 0.8$ & $E_{\text {pit }}$ & $1.0 \pm 0.0$ \\
\hline
\end{tabular}

to $50^{\circ} \mathrm{C}$ and $70^{\circ} \mathrm{C}$, the passive regions became narrow, and corrosion current densities $\left(I_{\text {corr }}\right)$ increased and the pitting potentials $\left(E_{\text {pit }}\right)$ decreased substantially (Table 2 ), which meant that the passive films degraded and the corrosion resistance decreased with the increasing of temperature. Moreover, current transients caused by activation and repassivation of metastable pitting [32] were observed, particularly at higher temperatures. The CrCoNiN alloy displays similar polarization behaviour with $\mathrm{CrCoNi}$ alloy at $30^{\circ} \mathrm{C}$, as shown in the inserted micrograph in Fig. 3(b). However, with the increasing of temperature, the corrosion current densities increased and pitting potentials decreased slightly (Table 2), and thus the passive film kept almost stable at high temperatures. Besides, the addition of nitrogen in $\mathrm{CrCoNi}$ alloy reduced the incidence of current transients. Therefore, it can be concluded that nitrogen alloying could inhibit the metastable pitting and enhance the pitting corrosion resistance of $\mathrm{CrCoNiN}$ alloy in high temperature chloride solution.

Fig. 3(c) and (d) shows the cyclic polarization curves of $\mathrm{CrCoNi}$ and $\mathrm{CrCoNiN}$ medium-entropy alloys. For $\mathrm{CrCoNi}$ alloy at $30^{\circ} \mathrm{C}$, the current density of the backward scan was lower than upward scan and the hysteresis loop did not appeared, which did not exhibit any pitting susceptibility. With increasing the temperatures to $50^{\circ} \mathrm{C}$ and $70^{\circ} \mathrm{C}$, the current densities continuously increased to maximum current densities $\left(I_{\max }\right)$ in the backward scans and hys- teresis loops were generated. The $I_{\max }$ increased and repassivation potential $\left(E_{\mathrm{rp}}\right)$ decreased with increasing temperature (Table 2), indicating the repassivation ability decreased and the pitting susceptibility increased at higher temperatures [33]. However, for CrCoNiN alloy, the cyclic polarization curve almost coincided with $\mathrm{CrCoNiN}$ at $30^{\circ} \mathrm{C}$, which was in accordance with the potentiodynamic polarization curves. The absence of hysteresis loops at $50^{\circ} \mathrm{C}$ and $70^{\circ} \mathrm{C}$ meant that $\mathrm{CrCoNiN}$ alloy exhibited low pitting susceptibility even at high temperatures. Thus, the addition of nitrogen effectively improved the repassivation ability and reduced the pitting susceptibility.

To elucidate the resistance to stable pitting growth of $\mathrm{CrCoNi}$ and $\mathrm{CrCoNiN}$ medium-entropy alloys in chloride solution at high temperature, CPT measurements were performed by potentiostatic polarization at $600 \mathrm{mV}_{\mathrm{SCE}}$ in $3.5 \mathrm{wt} \% \mathrm{NaCl}$ solution, as shown in Fig. 4. The current densities of both alloys gradually increased with the rise in temperature. The further raising of temperature induced sharp increasing of current densities, which indicated the occurrence of stable pitting. The CPT values were determined to be $49.8 \pm 3.7^{\circ} \mathrm{C}$ and $79.0 \pm 1.4^{\circ} \mathrm{C}$ for $\mathrm{CrCoNi}$ and $\mathrm{CrCoNiN}$ alloys, respectively. Compared with some commercial stainless steels (Table 3) [30,34-37], the CrCoNi alloy exhibits good corrosion resistance, and the addition of nitrogen further enhances its corrosion resistance in high temperature chloride solution. 
Table 3

Main alloying element contents and CPT values of commercial stainless steels in literatures.

\begin{tabular}{|c|c|c|c|c|c|c|}
\hline \multirow[t]{2}{*}{ Alloys } & \multicolumn{4}{|c|}{ Contents of main alloying elements (wt\%) } & \multirow[t]{2}{*}{$\mathrm{CPT}\left({ }^{\circ} \mathrm{C}\right)$} & \multirow[t]{2}{*}{ Testing solutions } \\
\hline & $\mathrm{Cr}$ & Mo & $\mathrm{N}$ & $\mathrm{Ni}$ & & \\
\hline $304[34]$ & 18 & 1 & l & 9 & 4.6 & $1 \mathrm{M} \mathrm{NaCl}$ \\
\hline $316 L[30]$ & 17.13 & 2.15 & l & 12.7 & 17.2 & $3.5 \mathrm{wt} \% \mathrm{NaCl}$ \\
\hline 904L [35] & 20.06 & 4.32 & l & 25.04 & 51.1 & $1 \mathrm{M} \mathrm{NaCl}$ \\
\hline 2101DSS [36] & 21.4 & 0.31 & 0.23 & 1.2 & 33 & $1 \mathrm{M} \mathrm{NaCl}$ \\
\hline 2304DSS [37] & 23.23 & 0.42 & 0.12 & 4.8 & 33 & $1 \mathrm{M} \mathrm{NaCl}$ \\
\hline
\end{tabular}

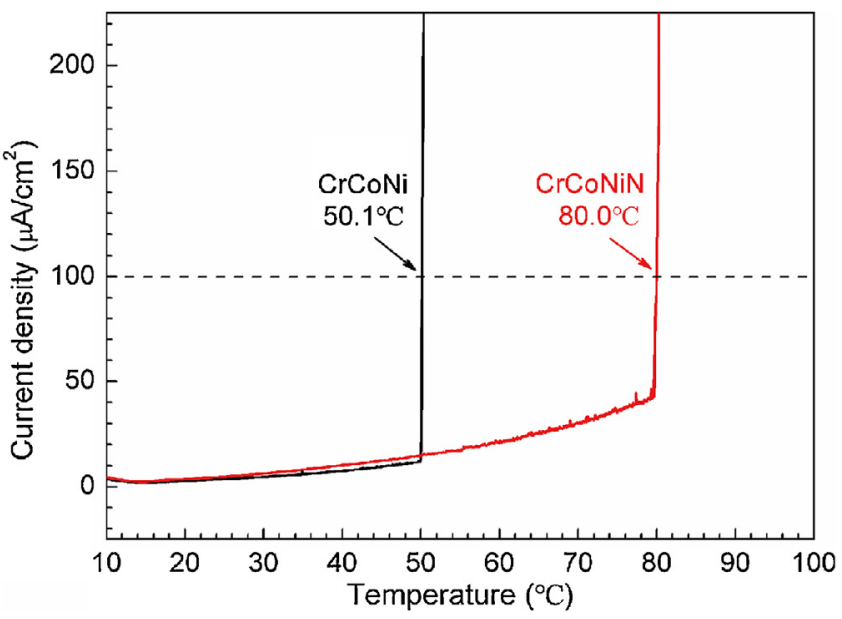

Fig. 4. Typical potentiostatic curves of $\mathrm{CrCoNi}$ and $\mathrm{CrCoNiN}$ medium-entropy alloys at $600 \mathrm{mV}_{\mathrm{SCE}}$ in $3.5 \mathrm{wt} \% \mathrm{NaCl}$ solution.

\subsection{Passive film analysis}

Fig. 5(a) shows the Mott-Schottky plots for passive films on $\mathrm{CrCoNi}$ and $\mathrm{CrCoNiN}$ medium-entropy alloys formed at $0 \mathrm{mV}_{\mathrm{SCE}}$ for $3600 \mathrm{~s}$ in $3.5 \mathrm{wt} \% \mathrm{NaCl}$ solution at different temperatures. The plots reveal that a linear relationship with a negative slope existed between $1 / C^{2}$ and $E$, which agrees well with the Mott-Schottky equation for $p$-type semiconductor, as expressed by Eq. (1) [38-41]:

$\frac{1}{C^{2}}=-\frac{2}{\varepsilon \varepsilon_{0} q N_{A}}\left(E-E_{F B}-\frac{k T}{q}\right)$

where $C$ represents the space charge capacitance, $\varepsilon$ the dielectric constant of the passive film (12.0), $\varepsilon_{0}$ the permittivity of free space $\left(8.854 \times 10^{-14} \mathrm{~F} / \mathrm{cm}\right), q$ the electron charge $\left(1.602 \times 10^{-19} \mathrm{C}\right), N_{A}$ the acceptor density, $E_{\mathrm{FB}}$ the flat band potential, $k$ the Boltzmann constant $\left(1.38 \times 10^{-23} \mathrm{~J} / \mathrm{K}\right)$, and $T$ the absolute temperature. The $N_{\mathrm{A}}$ values of passive films on $\mathrm{CrCoNi}$ and $\mathrm{CrCoNiN}$ alloys determined from the slope of $1 / C^{2}$ vs. $E$ are all of the order of $10^{21} \mathrm{~cm}^{-3}$ (Fig. 5(b)), which are in similar range of stainless steels $[39,42,43]$.
The $N_{\mathrm{A}}$ values for $\mathrm{CrCoNi}$ increased significantly with temperature, whereas the values for CrCoNiN slightly increased with temperature, and they were lower than CrCoNi alloy, especially at high temperatures. It indicates that the addition of nitrogen in $\mathrm{CrCoNi}$ alloy decreased the defect density, promoted the formation of less defective passive film and reduced its susceptibility to temperature.

Fig. 6(a) shows the XPS survey spectra of passive films on $\mathrm{CrCoNi}$ and $\mathrm{CrCoNiN}$ medium-entropy alloys. The elements $\mathrm{Ni}, \mathrm{Co}, \mathrm{Cr}, \mathrm{O}$ and $\mathrm{C}$ were recorded on both alloys, but $\mathrm{N}$ was not observed on $\mathrm{CrCoNiN}$ alloy due to its low content. The ratios of $\mathrm{Cr} /(\mathrm{Cr}+\mathrm{Ni}+\mathrm{Co})$ in the passive films increased with the addition of nitrogen in CrCoNi alloy (Fig. 6(b)), and the enrichment of $\mathrm{Cr}$ could improve the stability and corrosion resistance of passive film [42]. The variation of $01 \mathrm{~s}$ contents in the passive films with etching time is displayed in Fig. 6(c), and the etching time when the 01 s content reached half of the maximum value was used to estimate the thickness of passive film $[44,45]$. Considering that the sputtering rate was about $0.2 \mathrm{~nm} / \mathrm{s}$ (vs. $\mathrm{Ta}_{2} \mathrm{O}_{5}$ ) [46], the thickness of the passive films was increased from $3.56 \mathrm{~nm}$ for $\mathrm{CrCoNi}$ alloy to $5.61 \mathrm{~nm}$ for CrCoNiN alloy.

The XPS spectra of $\mathrm{Cr} 2 \mathrm{p}_{3 / 2}$, Co $2 \mathrm{p}_{3 / 2}$, Ni $2 \mathrm{p}_{3 / 2}$ and $\mathrm{O} 1 \mathrm{~s}$ recorded from the outmost surface of passive films on $\mathrm{CrCoNi}$ and $\mathrm{CrCoNiN}$ medium-entropy alloys are illustrated in Fig. 7. The $\mathrm{Cr} 2 \mathrm{p}_{3 / 2}$ spectra were separated into $\mathrm{Cr}(\mathrm{OH})_{3}(577.4 \mathrm{eV}), \mathrm{Cr}_{2} \mathrm{O}_{3}(576.0 \mathrm{eV})$ and $\mathrm{Cr}-$ met $(574.0 \mathrm{eV})$. The Co $2 \mathrm{p}_{3 / 2}$ spectra were split into $\mathrm{CoO}(780.0 \mathrm{eV})$ and Co-met $(778.1 \mathrm{eV})$. The Ni $2 \mathrm{p}_{3 / 2}$ spectra were dominated by $\mathrm{Ni}(\mathrm{OH})_{2}(855.6 \mathrm{eV}), \mathrm{NiO}(854.0 \mathrm{eV})$ and $\mathrm{Ni}-\mathrm{met}(852.6 \mathrm{eV})$, and the contents of $\mathrm{Ni}(\mathrm{OH})_{2}$ and $\mathrm{NiO}$ were decreased by adding nitrogen into $\mathrm{CrCoNi}$ alloy. The $\mathrm{O} 1 \mathrm{~s}$ spectra were divided into $\mathrm{OH}^{-}$ $(531.5 \mathrm{eV})$ and $\mathrm{O}^{2-}(529.8 \mathrm{eV})$, and hydroxides were the primary constituent on the outmost surface of the passive films.

Fig. 8 shows the XPS spectra of $\mathrm{N} 1 \mathrm{~s}$ recorded from the sputtering surfaces for $0 \mathrm{~s}, 10 \mathrm{~s}, 70 \mathrm{~s}$ and $170 \mathrm{~s}$ of the passive film on CrCoNiN alloy. On the outmost surface of the passive film, peaks representing $\mathrm{NH}_{4}{ }^{+}(400.3 \mathrm{eV}), \mathrm{NH}_{3}(399.5 \mathrm{eV}), \mathrm{Cr}_{2} \mathrm{~N}(397.6 \mathrm{eV})$ and $\mathrm{CrN}(396.6 \mathrm{eV})$ were detected. After sputtering for $10 \mathrm{~s}$, the peaks for $\mathrm{NH}_{4}{ }^{+}$and $\mathrm{NH}_{3}$ disappeared, and peaks representing $\mathrm{Cr}_{2} \mathrm{~N}$ and $\mathrm{CrN}$ increased. As the sputtering time prolonged to $70 \mathrm{~s}$ and $170 \mathrm{~s}$, the intensity of $\mathrm{CrN}$ decreased, indicating that the nitrogen was enriched in the passive film in the form of $\mathrm{CrN}$. However, the change
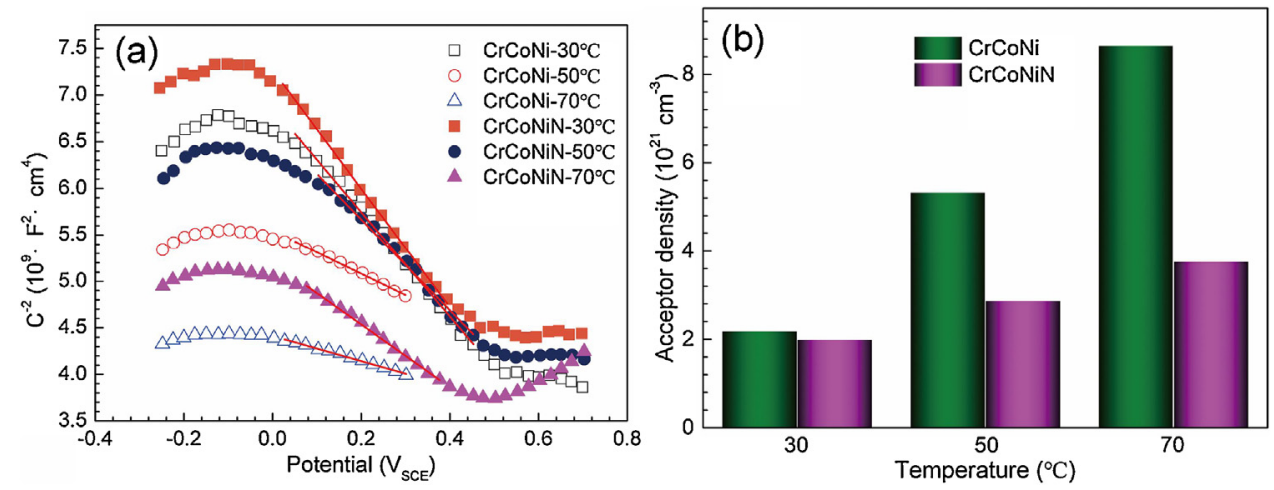

Fig. 5. (a) Mott-Schottky plots and (b) acceptor densities for passive films on CrCoNi and CrCoNiN medium-entropy alloys. 

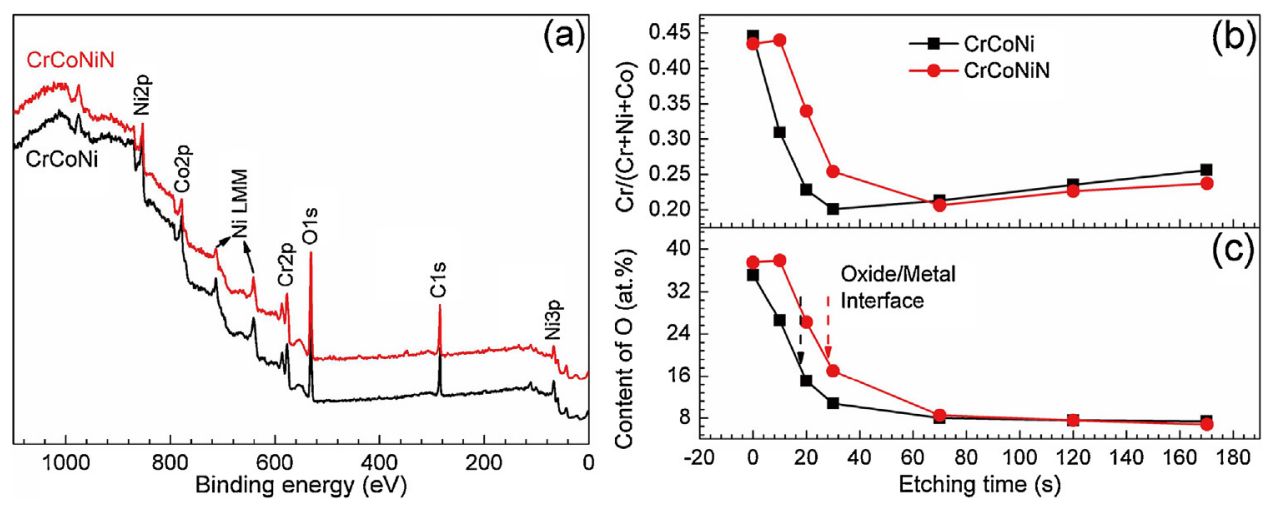

Fig. 6. (a) XPS spectra, (b) ratios of $\mathrm{Cr} /(\mathrm{Cr}+\mathrm{Ni}+\mathrm{Co})$ and (c) contents of $\mathrm{O} 1 \mathrm{~s}$ in the passive films on $\mathrm{CrCoNi}$ and $\mathrm{CrCoNiN}$ medium-entropy alloys.

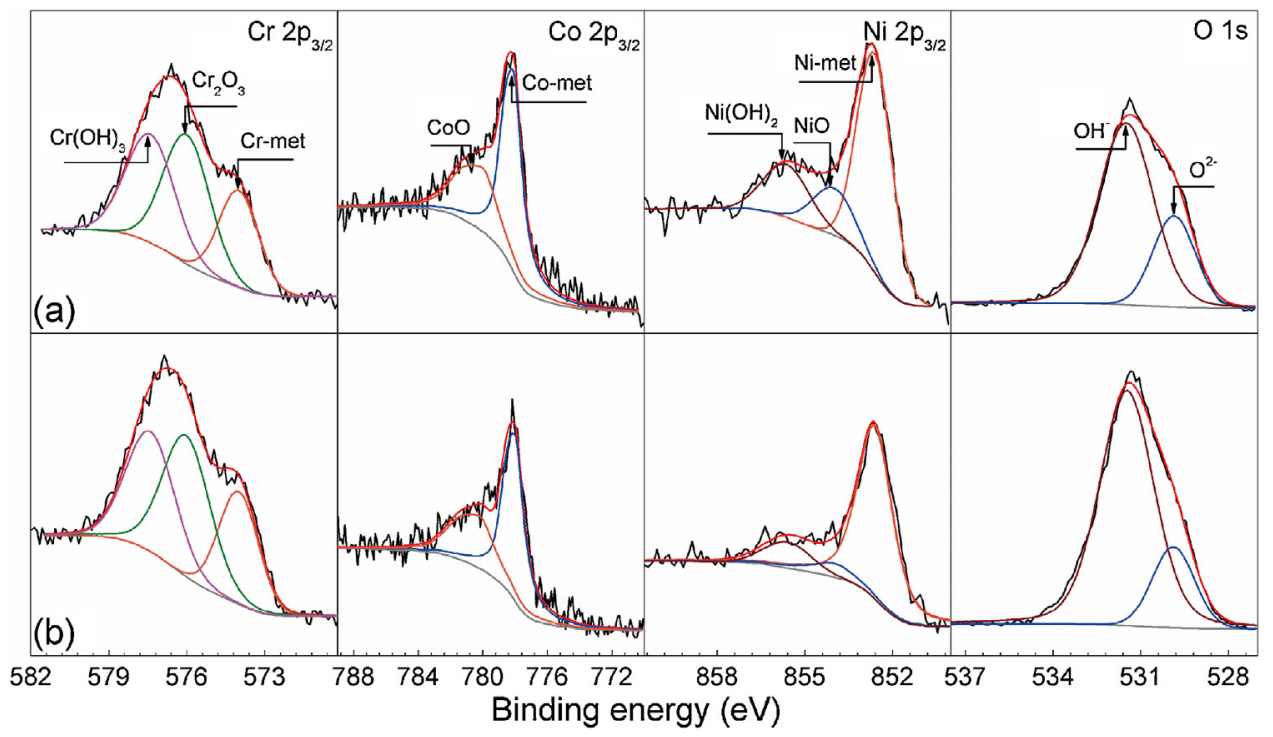

Fig. 7. XPS spectra of $\mathrm{Cr} 2 \mathrm{p}_{3 / 2}$, Co $2 \mathrm{p}_{3 / 2}$, Ni 2 $\mathrm{p}_{3 / 2}$ and $\mathrm{O} 1 \mathrm{~s}$ recorded from the outmost surface of passive films on (a) CrCoNi and (b) CrCoNiN medium-entropy alloys.

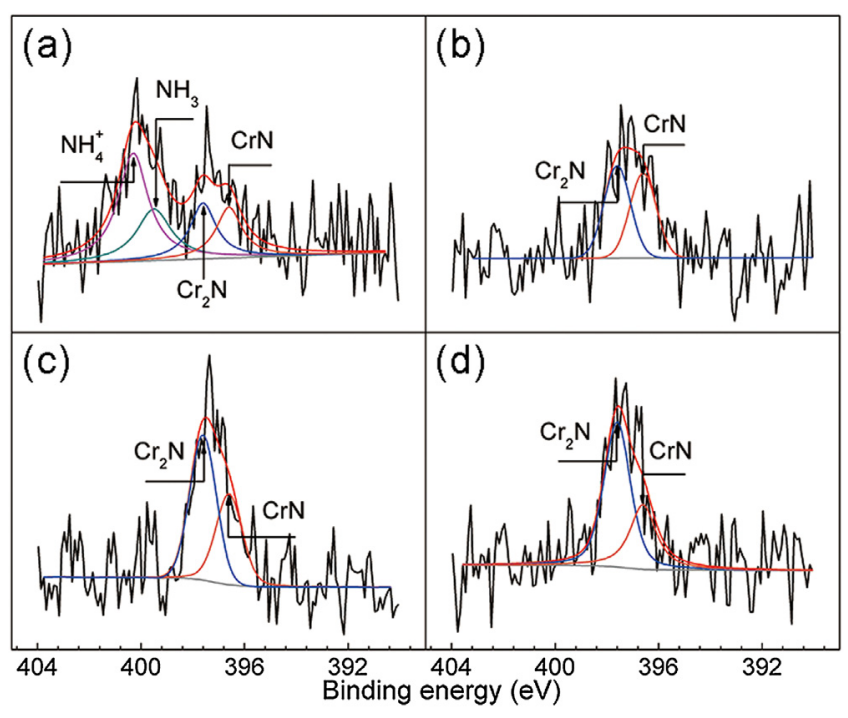

Fig. 8. XPS spectra of $\mathrm{N} 1 \mathrm{~s}$ recorded from the sputtering surfaces for (a) $0 \mathrm{~s}$, (b) $10 \mathrm{~s}$, (c) $70 \mathrm{~s}$ and (d) $170 \mathrm{~s}$ of the passive film on CrCoNiN medium-entropy alloy.

in intensity of $\mathrm{Cr}_{2} \mathrm{~N}$ with sputtering time was not obvious, which means that the $\mathrm{Cr}_{2} \mathrm{~N}$ in the passive film corresponded to $\mathrm{Cr}_{2} \mathrm{~N}$ precipitates which hardly changed with sputtering due to their large size.

\section{Discussion}

The addition of nitrogen in CrCoNi medium-entropy alloy induced the formation of $\mathrm{Cr}_{2} \mathrm{~N}$ precipitates and uniformly distributed $\mathrm{N}$ atoms, and then refined the grain size, reduced the defect density, enhanced the stability of passive film and significantly increased its corrosion resistance in high temperature chloride solution. Based on the above results, the effect of nitrogen on constitution, breakdown of passive film and the initiation of metastable pitting will be discussed in detail.

\subsection{Effect of nitrogen on constitution of passive film}

The significant increase in corrosion resistance of $\mathrm{CrCoNiN}$ medium-entropy alloy by adding nitrogen is closely related to the change in the constitution of passive film. The beneficial effects of nitrogen on passive films of austenitic and duplex stainless steels have been widely reported $[15,43,47]$. In the present study, the addition of nitrogen in $\mathrm{CrCoNi}$ alloy increased the thickness of passive film (Fig. 6(c)). However, Fu et al. [15] and Olefjord et al. [48] reported that nitrogen did not influence the thickness of passive film on austenitic stainless steels, which is inconsistent with our result. According to the work by Lee et al. [49] on $18 \mathrm{Cr}-10 \mathrm{Mn}$ $0.3 \mathrm{C}-0.3 \mathrm{~N}$ austenitic stainless steel, the addition of $\mathrm{Nb}$ decreased the grain size and increased the thickness of passive film, which was regarded as one of the primary reasons for the enhanced 

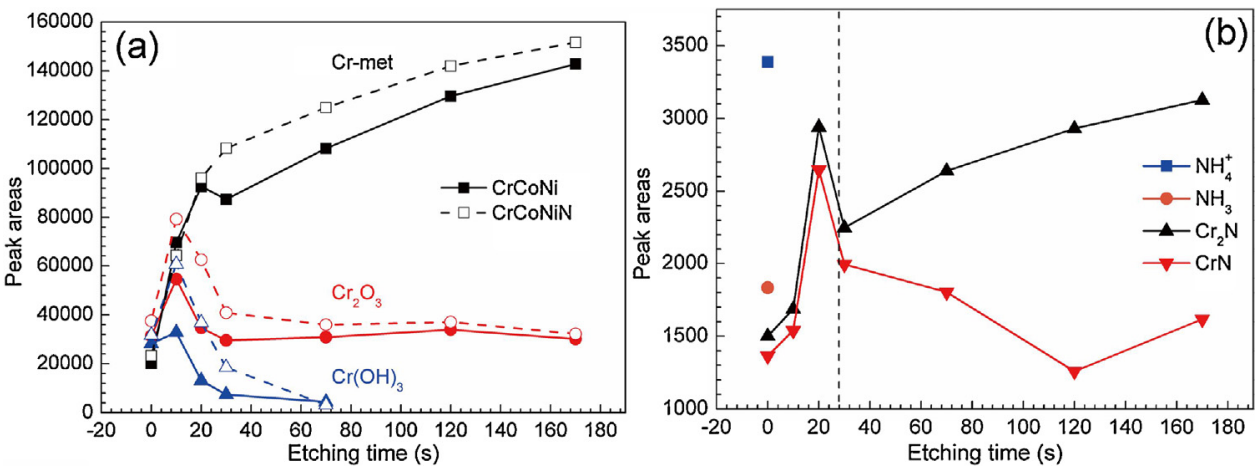

Fig. 9. Peak areas of species in (a) $\mathrm{Cr} 2 \mathrm{p}_{3 / 2}$ in the passive films on CrCoNi and CrCoNiN medium-entropy alloys and (b) $\mathrm{N} 1 \mathrm{~s}$ in the passive films on CrCoNiN alloy.

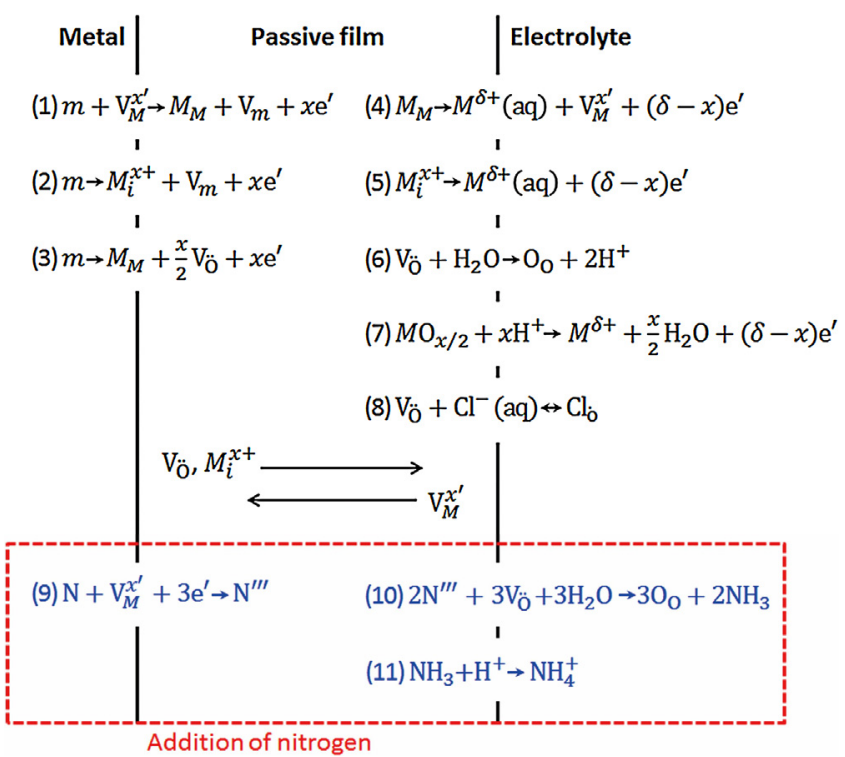

Fig. 10. Schematic diagram of physicochemical processes based on PDM model. $m=$ metal atom, $\mathrm{V}_{M}^{x^{\prime}}=$ cation vacancy, $M_{M}=$ metal cation in cation site, $\mathrm{V}_{m}=$ vacancy in metal site, $M_{i}^{x+}=$ cation interstitial, $\mathrm{V}_{\ddot{O}}=$ oxygen vacancy, $M^{\delta+}(\mathrm{aq})=$ metal cation in electrolyte, $\mathrm{O}_{\mathrm{O}}=$ oxygen ion in anion site, $\mathrm{Cl}^{-}(\mathrm{aq})=$ chloride ion in electrolyte, $\mathrm{Cl}_{\mathrm{o}}=$ oxygen vacancy occupied by $\mathrm{Cl}^{-}, \mathrm{N}=$ nitrogen atom, $\mathrm{N}^{\prime \prime \prime}=$ nitrogen ion.

corrosion resistance. Therefore, considering that adding nitrogen significantly refined the grain size of $\mathrm{CrCoNi}$ alloy, the volume fraction of grain boundaries was increased, which further enhanced the passivation reaction due to the promoted diffusion of passive elements and the increased reactivity $[49,50]$.

The enrichment of $\mathrm{Cr}$ in the passive films was observed on both CrCoNi and CrCoNiN alloys (Fig. 6(b)), and the addition of nitrogen further promoted the $\mathrm{Cr}$ enrichment, although the precipitation of $\mathrm{Cr}_{2} \mathrm{~N}$ in $\mathrm{CrCoNiN}$ alloy lowered the $\mathrm{Cr}$ content of the matrix. The promoted $\mathrm{Cr}$ enrichment and enhanced corrosion resistance by $\mathrm{N}$ was also reported by previous researchers on stainless steels $[16,20,43,51]$. As shown in Table 4, Ni and Co elements in the passive films on both alloys were depleted due to the higher diffusion rates of $\mathrm{Co}^{2+}$ and $\mathrm{Ni}^{2+}$ than that of $\mathrm{Cr}^{3+}$ [52], indicating that the preferential dissolution of $\mathrm{Co}$ and $\mathrm{Ni}$ into the electrolyte induced the enrichment of $\mathrm{Cr}$ in the passive films. Moreover, the severer depletion of $\mathrm{Ni}$ and $\mathrm{Co}$ in the passive film on $\mathrm{CrCoNiN}$ alloy means that $\mathrm{N}$ promoted their dissolution, and further improved the enrichment of $\mathrm{Cr}$, which is similar with the promoted selective dissolution of Fe by $\mathrm{N}$ in stainless steels $[16,20]$. The enrichment of $\mathrm{Cr}$ enhanced the stability of passive film on CrCoNiN alloy, and was responsible for its higher corrosion resistance. On the other hand, based on the deconvolution of XPS spectra (Fig. 9(a)), the contents of $\mathrm{Cr}_{2} \mathrm{O}_{3}$ in
Table 4

Contents of $\mathrm{Ni}$, Co and $\mathrm{Cr}$ elements in the passive films on medium-entropy alloys (at\%).

\begin{tabular}{|c|c|c|c|c|c|}
\hline \multirow[t]{2}{*}{ Elements } & \multirow[t]{2}{*}{ Alloys } & \multicolumn{4}{|c|}{ Etching time (s) } \\
\hline & & 0 & 10 & 20 & 30 \\
\hline \multirow[t]{2}{*}{$\mathrm{Ni}$} & CrCoNi & 5.75 & 25.06 & 31.66 & 31.14 \\
\hline & CrCoNiN & 7.74 & 17.28 & 26.49 & 32.53 \\
\hline \multirow[t]{2}{*}{ Co } & $\mathrm{CrCoNi}$ & 4.51 & 21.85 & 29.26 & 33.92 \\
\hline & CrCoNiN & 3.24 & 13.20 & 18.36 & 24.28 \\
\hline \multirow[t]{2}{*}{$\mathrm{Cr}$} & $\mathrm{CrCoNi}$ & 8.24 & 21.02 & 18.03 & 16.36 \\
\hline & CrCoNiN & 8.44 & 23.92 & 23.10 & 19.36 \\
\hline
\end{tabular}

passive film were also enhanced by adding nitrogen, which could improve the stability and protective ability of the passive film on CrCoNiN alloy [53].

Furthermore, nitrogen itself also made great contributions to the enhancement of corrosion resistance. The spectra (Fig. 8) together with the peak areas (Fig. 9(b)) of $\mathrm{N}$ 1s reveal the enrichment of ammonia $\left(\mathrm{NH}_{3}\right.$ and $\left.\mathrm{NH}_{4}{ }^{+}\right)$on the outmost surface of passive film and $\mathrm{CrN}$ at the metal/film interface on $\mathrm{CrCoNiN}$ alloy. The surface enrichment of $\mathrm{NH}_{3}$ and $\mathrm{NH}_{4}{ }^{+}$is also reported in nitrogen-alloyed stainless steels $[15,21,47]$. It is widely accepted that the formation of $\mathrm{NH}_{3}$ and $\mathrm{NH}_{4}{ }^{+}$could consume protons and enhance the $\mathrm{pH}$ value in incipient pits, thus promoting the repassivation of pits $[21,25,27,47,54]$, which agrees well with the higher repassivation potential of CrCoNiN alloy (Fig. 3(c) and (d)). On the other hand, based on the adsorption mechanism [19,55], the passive film was corroded by the absorbed $\mathrm{Cl}^{-}$ions. The $\mathrm{N}^{\prime \prime \prime}(\mathrm{CrN})$ in the metal/film interface would induce desorption of $\mathrm{Cl}^{-}$ions with the further thinning of passive film, thereby inhibiting the chlorination enhanced corrosion [19]. Moreover, the enriched $\mathrm{CrN}$ could improve the passive film by Eq. (2) [24,25,47,56]:

$2 \mathrm{CrN}+3 \mathrm{H}_{2} \mathrm{O}_{\text {ads }}=\mathrm{Cr}_{2} \mathrm{O}_{3}+2 \mathrm{NH}_{3}$ (ligand)

which induced the formation of $\mathrm{Cr}_{2} \mathrm{O}_{3}, \mathrm{NH}_{3}$ and even $\mathrm{NH}_{4}{ }^{+}$with further protonation [47]. Willenbruch et al. considered the enriched CrN beneath the passive film as a precursor to the formation of passive film [56]. Therefore, the addition of nitrogen contributed to the formation of thicker and more compact passive film of $\mathrm{CrCoNiN}$ alloy, and thus decreased the corrosion current density, enhanced the pitting potential, repassivation potential and CPT value.

\subsection{Effect of nitrogen on the breakdown of passive film}

The Mott-Schottky analyses show that the passive films on both alloys behaved as a $p$-type semiconductor, which was closely connected with the composition of the passive films [57]. Previous studies have shown that the passive film rich in $\mathrm{Cr}_{2} \mathrm{O}_{3}$, $\mathrm{Cr}(\mathrm{OH})_{3}, \mathrm{NiO}, \mathrm{FeO}$, etc. behaves as a $p$-type semiconductor, and the passive film rich in $\mathrm{Fe}_{2} \mathrm{O}_{3}, \mathrm{CrO}_{3}$, etc. behaves as an $n$-type semi- 


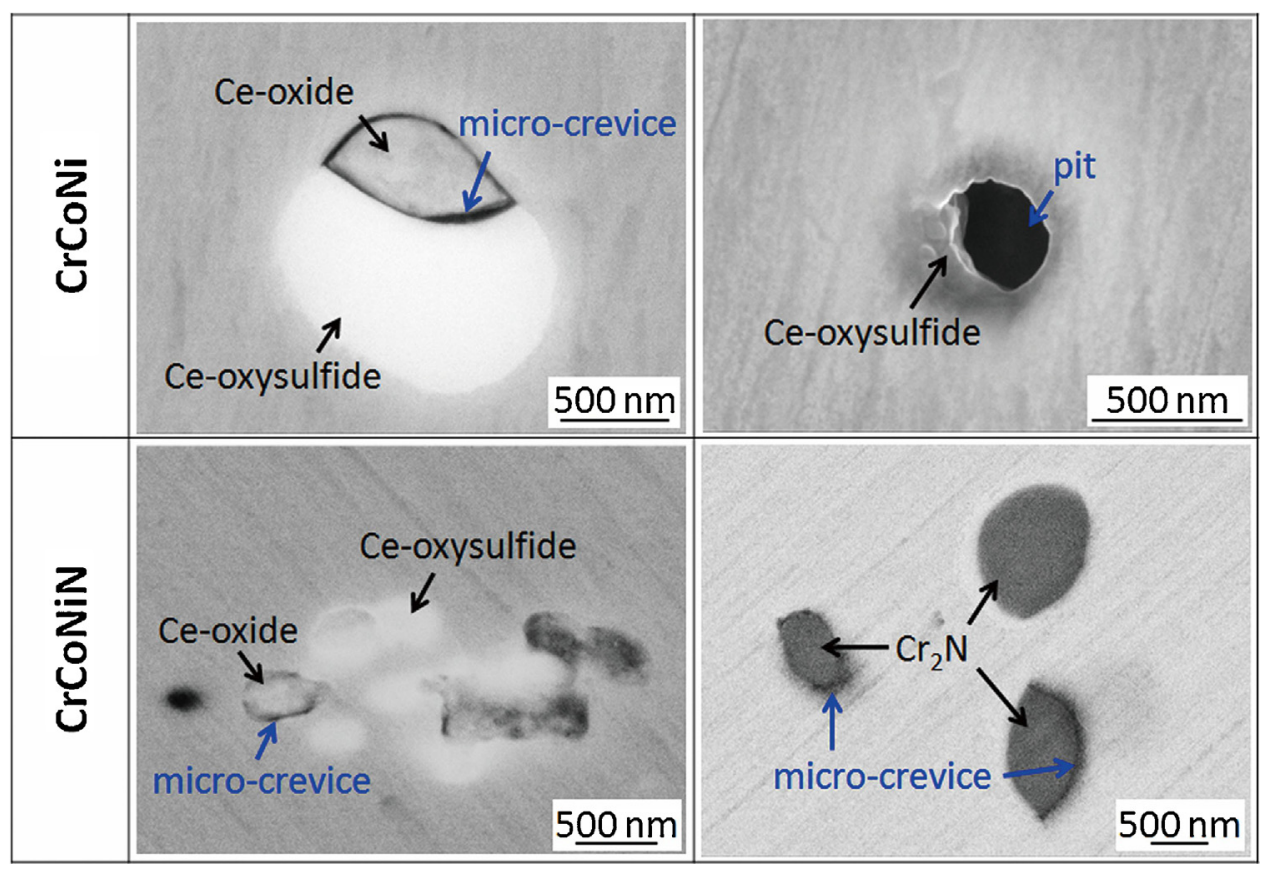

Fig. 11. Morphologies of pitting initiation sites of $\mathrm{CrCoNi}$ and $\mathrm{CrCoNiN}$ medium-entropy alloys.

(a)

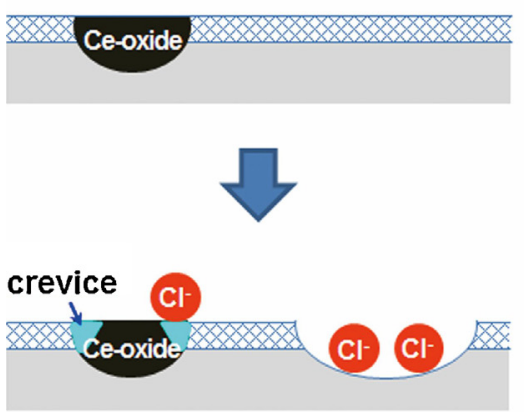

(b)
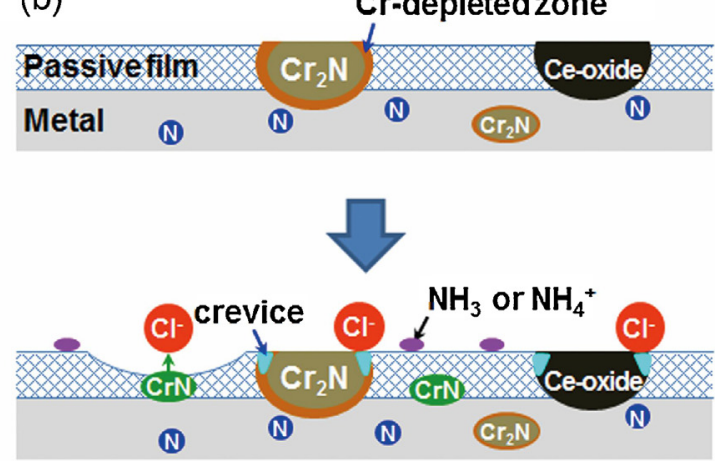

Fig. 12. Schematic diagrams of corrosion mechanism of (a) CrCoNi and (b) CrCoNiN medium-entropy alloys.

conductor $[53,58]$. In the present study, XPS results imply that the passive films were enriched in oxides and hydroxides of $\mathrm{Cr}$, Co and $\mathrm{Ni}$, and their $p$-type semiconductivity is consistent with the Mott-Schottky results. According to the point defect model (PDM) proposed by Macdonald $[43,59,60]$, the oxygen vacancies $\left(V_{\ddot{O}}\right)$ and cation interstitials $\left(M_{i}^{X+}\right)$ were created at the metal/film interface, and cation vacancies $\left(V_{M}^{x^{\prime}}\right)$ were created at the film/electrolyte interface. Afterwards, they migrated and diffused across the passive film, and finally annihilated at the opposite interfaces (Fig. 10). The increasing of temperature significantly increased the generation rate (Reaction 4) and diffusivity of cation vacancies but decreased their annihilation rate (Reaction 1) [61], which induced the condensation of cation vacancies at the metal/film interface. Thereafter, the passive film detached locally from the metal and ceased to grow, whereas it continued to dissolve at the film/electrolyte interface, which would result in the breakdown of passive film and the initiation of pitting corrosion $[59,61]$. The above processes agree well with the higher acceptor density and lower passive film stability of CrCoNi alloy in the present work.

However, in CrCoNiN alloy, the acceptor density was remarkably reduced, in accordance with its higher $\mathrm{Cr}^{\prime \prime \prime}\left(\mathrm{Cr}_{2} \mathrm{O}_{3}+\mathrm{Cr}(\mathrm{OH})_{3}\right)$ concentration (Fig. 9(a)). Moreover, the generation of nitrogen ions
$\left(\mathrm{N}^{\prime \prime \prime}\right)$, confirmed by the enrichment of $\mathrm{CrN}$ at the metal/film interface (Fig. 9(b)), could consume cation vacancies by Reaction 9. At the film/electrolyte interface, $\mathrm{N}^{\prime \prime \prime}$ could react with the $\mathrm{H}^{+}$formed by Reaction 6 , thus consuming the oxygen vacancies and enhancing the content of $\mathrm{O}_{\mathrm{O}}$ (Reaction 10). This coincides with the higher oxygen content in $\mathrm{CrCoNiN}$ than $\mathrm{CrCoNi}$ alloy in the present study and the result by Wang et al. [62]. The formation of $\mathrm{NH}_{3}$ could consume $\mathrm{H}^{+}$(Reaction 11), and reduce the corroding of the passive film. Moreover, the lower oxygen vacancy density could also restrain the adsorption of $\mathrm{Cl}^{-}$(Reaction 8). The addition of nitrogen in $\mathrm{CrCoNi}$ alloy significantly decreased the density of point defects, and then decreased the breakdown susceptibility of passive film. As a consequence, the stability of passive film was enhanced, in turn, resulting in the improvement of the corrosion resistance.

\subsection{Effect of nitrogen on the metastable pitting}

To investigate the effect of nitrogen alloying on metastable pitting behaviour of $\mathrm{CrCoNi}$ medium-entropy alloys, the morphologies of two alloys after cyclic polarization tests in $3.5 \mathrm{wt} \% \mathrm{NaCl}$ solution at $30^{\circ} \mathrm{C}$ were observed using FE-SEM, as shown in Fig. 11. The micro-crevice was observed around Ce-oxide inclusion in $\mathrm{CrCoNi}$ 
alloy, but no crevice existed around Ce-oxysulfide inclusion. This reveals that metastable pitting preferentially initiated around the Ce-oxide inclusions, and the micro-crevice might propagate to become stable pits [32]. Recently, Liu et al. [63] reported that pitting corrosion in Q460NH weathering steel initiated by the dissolution of $(\mathrm{RE})_{2} \mathrm{O}_{2} \mathrm{~S}-(\mathrm{RE})_{x} \mathrm{~S}_{y}$ inclusions due to their lower Volta potential. In the present study, the preferential initiation of pitting corrosion around Ce-oxide might also associate with its lower Volta potential, and the work will be conducted in our further study.

In $\mathrm{CrCoNiN}$ alloy, the metastable pitting corrosion around Ceoxide was also observed (Fig. 11). With the same deoxidization and desulfurization process, the inclusions in both alloys were almost identical, which would induce similar metastable pitting susceptibility. Meanwhile, the micro-crevices were found around $\mathrm{Cr}_{2} \mathrm{~N}$ precipitates as well. In general, the $\mathrm{Cr}$-rich precipitates are detrimental to corrosion resistance due to the formation of Cr-depleted zones [21,28]. Besides, the high-density dislocation piled up around $\mathrm{Cr}_{2} \mathrm{~N}$ (Fig. 1(f)) could reduce the energy barrier for electrochemical reactions, provide more active sites, and hence increase the corrosion rate [64]. However, in this study, CrCoNiN alloy exhibited the lower metastable pitting susceptibility. The reasons can be summarized as two groups: firstly, nitrogen in the solid solution could react as $\mathrm{NH}_{3}$ and increase the $\mathrm{pH}$ value on the film/electrolyte interface, which inhibited the generation of metastable pitting. Secondly, a passive film with fewer defects can cover CrCoNiN alloy surface, subsequently, resulting in the lower metastable pitting susceptibility, which can be attributed to the higher $\mathrm{Cr}$ content of $\mathrm{CrCoNiN}$ alloy.

The corrosion mechanisms of $\mathrm{CrCoNi}$ and $\mathrm{CrCoNiN}$ mediumentropy alloys are schematically presented in Fig. 12. In $\mathrm{CrCoNi}$ alloy, metastable pitting initiated around Ce-oxides in chloride solution, especially at high temperatures, and the passive film dissolved due to the adsorption of chloride ions. For CrCoNiN alloy, firstly, nitrogen atoms improved the corrosion resistance of both $\mathrm{Cr}$-depleted zones and the matrix around the inclusions. Moreover, the thicker, less defective and more compact passive film enhanced its stability and protective ability. In addition, the generation of ammonia on the outmost surface of passive film and $\mathrm{CrN}$ at the metal/film interface could buffer local $\mathrm{pH}$ and repel chloride ions, respectively. The above effects by nitrogen alloying through pressurized metallurgy decreased the metastable pitting susceptibility and increased the corrosion resistance of $\mathrm{CrCoNi}$ alloy.

\section{Conclusions}

In this study, the effects of nitrogen alloying on microstructure and pitting corrosion resistance of CrCoNiN medium-entropy alloy were investigated. The main conclusions could be obtained as follows:

1. Nitrogen existed in the form of $\mathrm{Cr}_{2} \mathrm{~N}$ precipitates and uniformly distributed $\mathrm{N}$ atoms, and the addition of nitrogen significantly refined the grain size of $\mathrm{CrCoNiN}$ alloy.

2. Nitrogen alloying inhibited the initiation of metastable pitting, remarkably decreased corrosion current densities, increased the pitting and repassivation potentials and CPT values of $\mathrm{CrCoNiN}$ alloy. Metastable pitting initiated around Ce-oxide inclusions and $\mathrm{Cr}_{2} \mathrm{~N}$ precipitates.

3. The passive films on both alloys exhibited $p$-type semiconductor behaviour. The addition of nitrogen decreased the acceptor density, increased the thickness of passive film and promoted the enrichment of $\mathrm{Cr}$ and $\mathrm{Cr}_{2} \mathrm{O}_{3}$ in the passive film. Meanwhile, the enrichment of ammonia $\left(\mathrm{NH}_{3}\right.$ and $\left.\mathrm{NH}_{4}{ }^{+}\right)$on the outmost surface of passive film and $\mathrm{CrN}$ at the metal/film interface on $\mathrm{CrCoNiN}$ alloy enhanced the protective ability of passive film.

\section{Acknowledgements}

This work was supported by the National Natural Science Foundation of China (Grant Nos. 51434004, U1435205, 51774074) and the Transformation Project of Major Scientific and Technological Achievements in Shenyang (Grant No. Z17-5-003). We acknowledge Prof. Wenqing Liu for APT experiment support and relevant discussion.

\section{References}

[1] J.W. Yeh, S.K. Chen, S.J. Lin, J.Y. Gan, T.S. Chin, T.T. Shun, C.H. Tsau, S.Y. Chang, Adv. Eng. Mater. 6 (2004) 299-303.

[2] Y. Zhang, T.T. Zuo, Z. Tang, M.C. Gao, K.A. Dahmen, P.K. Liaw, Z.P. Lu, Prog. Mater. Sci. 61 (2014) 1-93.

[3] J.W. Yeh, Ann. Chim. Sci. Mater. 31 (2006) 633-648.

[4] F. Otto, A. Dlouhy, C. Somsen, H. Bei, G. Eggeler, E.P. George, Acta Mater. 61 (2013) 5743-5755.

[5] B. Gludovatz, A. Hohenwarter, K.V.S. Thurston, H. Bei, Z. Wu, E.P. George, R.O. Ritchie, Nat. Commun. 7 (2016) 10602.

[6] H. Jiang, L. Jiang, D. Qiao, Y. Lu, T. Wang, Z. Cao, T. Li, J. Mater. Sci. Technol. 33 (2017) 712-717

[7] C. Zhang, F. Zhang, H. Diao, M.C. Gao, Z. Tang, J.D. Poplawsky, P.K. Liaw, Mater. Des. 109 (2016) 425-433.

[8] G. Laplanche, A. Kostka, C. Reinhart, J. Hunfeld, G. Eggeler, E.P. George, Acta Mater. 128 (2017) 292-303.

[9] I. Moravcik, J. Cizek, Z. Kovacova, J. Nejezchlebova, M. Kitzmantel, E. Neubauer, I. Kubena, V. Hornik, I. Dlouhy, Mater. Sci. Eng. A 701 (2017) 370-380.

[10] Y.L. Zhao, T. Yang, Y. Tong, J. Wang, J.H. Luan, Z.B. Jiao, D. Chen, Y. Yang, A. Hu, C.T. Liu, J.J. Kai, Acta Mater. 138 (2017) 72-82.

[11] Z. Wang, I. Baker, Mater. Lett. 180 (2016) 153-156.

[12] Z. Wang, I. Baker, Z. Cai, S. Chen, J.D. Poplawsky, W. Guo, Acta Mater. 120 (2016) 228-239.

[13] C.P. Lee, Y.Y. Chen, C.Y. Hsu, J.W. Yeh, H.C. Shih, J. Electrochem. Soc. 154 (2007) C424-C430.

[14] C.L. Briant, R.A. Mulford, E.L. Hall, Corrosion 38 (1982) 468-477.

[15] Y. Fu, X.Q. Wu, E.H. Han, W. Ke, K. Yang, Z.H. Jiang, Electrochim. Acta 54 (2009) 4005-4014

[16] J.B. Lee, S.I. Yoon, Mater. Chem. Phys. 122 (2010) 194-199.

[17] H.B. Li, E.Z. Zhou, Y.B. Ren, D.W. Zhang, D.K. Xu, C.G. Yang, H. Feng, Z.H. Jiang, X.G. Li, T.Y. Gu, K. Yang, Corros. Sci. 111 (2016) 811-821.

[18] H.B. Li, Z.H. Jiang, H. Feng, S.C. Zhang, L. Li, P.D. Han, R.D.K. Misra, J.Z. Li, Mater. Des. 84 (2015) 291-299.

[19] G. Lothongkum, P. Wongpanya, S. Morito, T. Furuhara, T. Maki, Corros. Sci. 48 (2006) 137-153.

[20] S.J. Pawel, E.E. Stansbury, C.D. Lundin, Corrosion 45 (1989) 125-133.

[21] Z.H. Jiang, H. Feng, H.B. Li, H.C. Zhu, S.C. Zhang, B.B. Zhang, Y. Han, T. Zhang, D.K. Xu, Materials 10 (2017) 861

[22] X. Oi, H. Mao, Y. Yang, Corros. Sci. 120 (2017) 90-98.

[23] R.F.A. Jargelius-Pettersson, Corros. Sci. 41 (1999) 1639-1664

[24] H.Y. Ha, T.H. Lee, S.J. Kim, Electrochim. Acta 80 (2012) 432-439.

[25] P.R. Levey, A. Vanbennekom, Corrosion 51 (1995) 911-921.

[26] C. Kowanda, M.O. Speidel, Scripta Mater. 48 (2003) 1073-1078.

[27] H.B. Li, Z.H. Jiang, Y. Cao, Z.R. Zhang, Int. J. Min. Met. Mater. 16 (2009) 387-392.

[28] H.B. Li, W.C. Jiao, H. Feng, Z.H. Jiang, C.D. Ren, Acta Metall. Sin. (Engl. Lett.) 29 (2016) 1148-1160.

[29] X.L. Wu, xlwu@imech.ac.cn, private communication, Beijing, October 2017.

[30] J. Liu, T. Zhang, G. Meng, Y. Shao, F. Wang, Corros. Sci. 91 (2015) 232-244.

[31] Database for surface spectroscopies as XPS, AES and UPS, http://www. lasurface.com, October 10, 2017.

[32] G. Frankel, J. Electrochem. Soc. 145 (1998) 2186-2198.

[33] H.B. Li, Z.H. Jiang, H. Feng, Q. Wang, W. Zhang, G.W. Fan, G.P. Li, L.Y. Wang, Int J. Electrochem. Sci. 10 (2015) 1616-1631.

[34] W. Zhang, L.Z. Jiang, J.C. Hu, S.H. Mei, Mater. Sci. Eng. A 497 (2008) 501-504

[35] M.H. Moayed, N.J. Laycock, R.C. Newman, Corros. Sci. 45 (2003) 1203-1216.

[36] L. Zhang, Y. Jiang, B. Deng, W. Zhang, J. Xu, J. Li, Mater. Charact. 60 (2009) $1522-1528$.

[37] H. Tan, Z. Wang, Y. Jiang, D. Han, J. Hong, L. Chen, L. Jiang, J. Li, Corros. Sci. 53 (2011) 2191-2200.

[38] Z.J. Liu, X.Q. Cheng, S.J. Lu, X.G. Li, Acta Metall. Sin. (Engl. Lett.) 23 (2010) 431-438.

[39] G. Meng, Y. Li, Y. Shao, T. Zhang, Y. Wang, F. Wang, J. Mater. Sci. Technol. 30 (2014) 253-258.

[40] T. Zhang, Y. Shao, G. Meng, Y. Li, F. Wang, Electrochim. Acta 52 (2006) 1323-1328.

[41] Y. Qiao, X. Cai, J. Cui, H. Li, Adv. Mater. Sci. Eng. 2016 (2016) 6065481.

[42] Z. Cui, L. Wang, H. Ni, W. Hao, C. Man, S. Chen, X. Wang, Z. Liu, X. Li, Corros. Sci. 118 (2017) 31-48

[43] H.Y. Ha, H.J. Jang, H.S. Kwon, S.J. Kim, Corros. Sci. 51 (2009) 48-53.

[44] R. Jiang, Y. Wang, X. Wen, C. Chen, J. Zhao, Appl. Surf. Sci. 412 (2017) 214-222.

[45] S. Mischler, A. Vogel, H.J. Mathieu, D. Landolt, Corros. Sci. 32 (1991) 925-944.

[46] J.B. Huang, X.Q. Wu, E.H. Han, Corros. Sci. 52 (2010) 3444-3452.

[47] C.O.A. Olsson, Corros. Sci. 37 (1995) 467-479. 
[48] I. Olefjord, L. Wegrelius, Corros. Sci. 38 (1996) 1203-1220.

[49] C.G. Lee, H.Y. Ha, T.H. Lee, K.M. Cho, J. Electrochem. Soc. 164 (2017) C591-C597.

[50] L. Liu, Y, Li, F. Wang, J. Mater. Sci. Technol. 26 (2010) 1-14.

[51] C.R. Clayton, K.G. Martin, High Nitrogen Steels - HNS 88, Institute of Metals, Lille, 1988, pp. 256-260.

[52] J. Robertson, Corros. Sci. 29 (1989) 1275-1291.

[53] Y. Yang, X. Ning, H. Tang, L. Guo, H. Liu, Appl. Surf. Sci. 320 (2014) 274-280.

[54] K. Osozawa, N. Okato, Passivity and Breakdown on Iron and Iron Based Alloys, NACE, Honolulu, 1976, pp. 135-139.

[55] H.J. Grabke, ISIJ Int. 36 (1996) 777-786.
[56] R.D. Willenbruch, C.R. Clayton, M. Oversluizen, D. Kim, Y. Lu, Corros. Sci. 31 (1990) 179-190.

[57] N.E. Hakiki, Corros. Sci. 53 (2011) 2688-2699.

[58] L.Q. Guo, M.C. Lin, L.J. Qiao, A.A. Volinsky, Corros. Sci. 78 (2014) 55-62.

[59] D.D. Macdonald, J. Electrochem. Soc. 139 (1992) 3434-3449.

[60] D.D. Macdonald, Electrochim. Acta 56 (2011) 1761-1772.

[61] K. Park, S. Ahn, H. Kwon, Electrochim. Acta 56 (2011) 1662-1669.

[62] K.S. Wang, S. Tong, M.K. Lei, J. Electrochem. Soc. 162 (2015) C601-C609.

[63] C. Liu, R.I. Revilla, Z. Liu, D. Zhang, X. Li, H. Terryn, Corros. Sci. 129 (2017) 82-90.

[64] T. Balusamy, T.S.N. Sankara Narayanan, K. Ravichandran, I.S. Park, M.H. Lee, Corros. Sci. 74 (2013) 332-344. 